\title{
Optimization of the capital structure of an agricultural company in the Czech Republic
}

\author{
Jaromír Vrbka ${ }^{1}$, Eva Kalinová2 ${ }^{*}$, and Zuzana Dvoř́ḱková $^{1}$ \\ ${ }^{1}$ Institute of Technology and Business in České Budějovice, School of Expertness and Valuation, \\ Okružní 517/10, 37001 České Budějovice, Czech Republic \\ ${ }^{2}$ University of Žilina, The Faculty of Operation and Economics of Transport and Communications, \\ Department of Economics, Univerzitná 8215/1, 01026 Žilina, Slovakia
}

\begin{abstract}
The topic of optimizing capital structure is very important for a company to work efficiently and reliably. It is important for every company to optimize everything so that they have the highest possible efficiency. Entrepreneurs also try to make this optimization last them as long as possible. Therefore, the aim of this paper is to determine the optimal capital structure of an agricultural company operating in the Czech Republic. The base source of data is the closing data of individual agricultural companies from the Albertina database of Bisnode. More than 9,000 agricultural enterprises operating in the given sector of the national economy in the Czech Republic are recorded in this data set. The calculation of the WACC method and the level of debt of individual agricultural companies are used. Subsequently, the equation for calculating the cost of capital is determined using power regression. Here we also obtain the value of reliability, which in this particular case is not ideal, but still reasonable. A line chart is used to determine the optimal interval for the agricultural company. The optimal debt interval comes out to 20 to $25 \%$, at which the cost of capital is declared to be from 22 to $24 \%$. If agricultural companies had higher or lower debt ratios, it would be inefficient for the enterprise.
\end{abstract}

Keywords: Optimal capital structure, debt, power regression, cost of capital, agriculture, optimization

JEL codes: D24, Q14

\section{Introduction}

The decision regarding the capital structure of a company is very important, because a bad decision can affect the profitability of the company, which leads to a reduction in shareholder value $[1,2]$. Good financial decisions can increase the market value of equity and bad financial decisions can reduce it [3]. An optimal capital structure is a key prerequisite for a business, although the determining of an optimal capital structure is difficult [4]. The available studies represent many different and contradictory factors that need to be taken into account in managers' strategic financial decisions. Their importance and intensity differ for individual business entities [5].

\footnotetext{
* Corresponding author: kalinova@mail.vstecb.cz
} 
When making the correct adjustment of the capital structure, more precisely the ratio of equity and debt, it is necessary to take into account a number of factors affecting the capital structure, such as various sources of financing $[3,6]$. Using factor analysis, three key external factors that entrepreneurs came up with were derived: the economic and political development of the country, the market environment of the country and the rates of taxes and interest rates [7]. European agricultural activity makes a significant contribution to European and global food supply, as well as to the preservation of the landscape and livelihoods. The main objective of this paper is to analyze the sustainability of agriculture in the 28 Member States of the European Union in order to promote sustainable agriculture, food security and rural development in the European region [8].

The measurement is then valid for all companies in the industry. Based on the results of the empirical study, the relationship of one of the factors in the Czech dairy sector is not constant. This limits the recommendation to use a common model for all companies in one sector. When making financial decisions, it is necessary to analyze the individual ability of a company to use foreign capital after quantifying the factors of the capital structure [9]. "Powerful managers" have a capital structure that differs significantly from "inefficient management" cooperatives [10]. The aim of the paper is to determine the optimization of the capital structure of companies focused on agriculture. The following research questions were set out to achieve the goal of the paper:

RQ1: What is the relationship between the price of capital and a company's debt ratio?

RQ2: What is the optimal capital structure?

\section{Literature research}

Woltz and Pencáková [11] found that in the Czech Republic, agricultural production is characterized by a dualistic structure, i.e. private farmers on the one hand and corporate farms on the other. According to Hudečková and Lošták [12], the dual concept of social capital makes it possible to explain some circumstances that can be presented in a relatively simplified manner in the case of a one-way orientation of understanding social capital. In 2007, Ortman and King [13] introduced cooperative theories and a new theory of institutional economics (including transaction cost economics, agency theory, and property rights theory) and its applicability. They are also presented in the organizational form of a cooperative, as well as the inherent problems of conventional cooperatives, namely free-rider, horizon, portfolio, monitoring and influencing cost issues caused by vaguely defined property rights. According to Stekla and Grycová [14], companies can use debt or equity to finance their assets. The best option is to mix debt and equity. The effect of capital structure decisions on a company's profitability and value is that it increases value through the present value of tax savings from the use of debt. Byer and Hinke [15] described the resulting differences in profitability broken down using the additive decomposition method, which addresses the quantified impact of several influencing factors. More profitable companies were less dependent on debt financing, while fast-growing companies had limited access to the financial market, said Fenyves et al. [16].

Keishinick and Moussawi [17] interpret their evidence by suggesting that, over time, managers allow their risk preferences to dominate their firm decisions about capital structure when protected from being disciplined. Yen, Miranda and Katchova [18] found that longterm use and size of debt have a positive impact on cooperative growth, which is contrary to Gibrat's law, which assumes that the size and growth of a company are independent. Cash flow, unallocated capital and long-term debt financing in particular make a decisive contribution to the growth of the assets of small and medium-sized cooperatives.

Wysokiński et al. [19] state that modern agriculture depends on industrial energy sources and on how socio-economic developments are changing into increasingly energy-intensive 
production technologies. Dimitrova [20] is convinced that society can focus on compliance with certain values of the indicator - these are the values that, according to the financial management of the company, if achieved, will mean that there will be no serious problems in repaying current liabilities. Kalusova and Bedura [21] used the methods of multiple regression and correlation analysis as the main research methods. The results showed that, in addition to internal business factors, external macro-environmental factors were also statistically highly significant for certain groups of agricultural enterprises. Wang [22] states that when the model is solved numerically on a numerical illustration, in equilibrium, an optimal capital structure is derived for an agricultural cooperative. The effects of changes in personal income tax rates and discount rates are also examined. The calculation of economic income is a reasonable way to calculate the requirements for economic viability [23]. Zeshan [24] argues that the WACC variable is selected as a dependent variable, while the Quality of Corporate Governance (QCG) variable was used as an independent variable. The endogeneity of the QCG variable was investigated using the 2SLS model, and the results show that the QCG variable significantly and negatively affects the WACC variable. In addition, the variables of leverage, ROA, revenue growth and stock volatility have significant positive links with WACC, while company size does have a significant negative relationship with WACC.

The increase in production compared to the farm's equity plays a crucial role in increasing profitability for all groups of farms but is especially important for smaller entities. In addition, agricultural company managers should monitor the level of debt, as the debt-to-assets ratio is a highly significant negative determinant of farm profitability in most groups. An increase in the subsidy rate is usually reflected in a higher ROA, but this variable has a negative impact on the largest enterprises [25]. Belás, Gaurová and Tóth [5] used ordinal logistic regression and estimated five models. These models were used to predict the SME attitude towards the capital structure. The analysis was performed in R Software. The main finding is that the size of the company measured by the number of employees affects its attitude to the volume of foreign and equity capital used to finance its activities.

A regression analysis is selected for this work to determine the optimal capital structure for agricultural enterprises in the Czech Republic. The debt ratio of selected agricultural enterprises in the Czech Republic will be assessed. The detected data is transferred to a scatter plot.

\section{Data and methods}

The source for finding important information that will help us calculate the optimal capital structure will be a file that contains the closing results of individual agricultural holdings. The WACC method is used to determine the optimization of individual companies and the regression analysis method is used to learn the optimal capital structure from all companies. The file contains a table listing information on 9,814 agricultural companies that had final accounts at the end of the accounting year (material, inventory, capital, etc.), but also contains personal data (name, ID number, place of business etc.) on individual companies. The columns needed to calculate the optimal capital structure will be added to the table. The data is downloaded from Bisnode's Albertina database.

First, the total equity, total debt and total capital of individual companies will be added up. We also need to add up the individual costs for debt and equity. Once we have this completed, we will calculate the optimization for all companies. We calculate it using the WACC method. The formula for this method is: 


$$
W A C C=E / C * r e+D / C * r d *(1-t)
$$

where:

$W A C C$ - weighted average cost of capital,

$E$ - equity,

$D$ - debt,

$C$ - total value of capital (equity plus debt),

$r_{e}$ - cost of equity,

$r_{d}$ - cost of debt,

$t$ - tax rate.

Another value will be needed to represent individual companies, namely the ratio of debt This will be calculated using the formula:

$$
\text { debt ratio }=D / C
$$

Once all the unknowns for each farm have been identified, they will be able to be plotted under the coordinates $[\mathrm{x} ; \mathrm{y}]$. The variable $\mathrm{x}$ (independent) will show the debt ratio and the variable y (dependent) will show the cost of capital. The individual points will be scattered over the entire area of the chart, so we will have to determine the position of the line. The general power regression formula is used: $y=b_{1} * x^{b 2}$, but this equation is nonlinear. Therefore, we adjust this equation to the form:

$$
\ln (y)=\ln (b 1)+b 2 * \ln (x)
$$

where:

$y$ - represents the cost of capital,

$x$ - debt ratio,

$b_{1}$ - first parameter,

$b_{2}$ - second parameter.

Using power regression, we calculate the parameters $\ln \left(b_{1}\right)$ and $b_{2}$. We will use the LinkRegression function in Excel. Once we know the parameters $b_{2}$ and $\ln \left(b_{1}\right)$, we will have to obtain the parameter $b_{1}$, de-logarithmize parameter $\ln \left(b_{1}\right)$. To determine the optimal capital structure for an agricultural enterprise, we use differentiation to calculate the minimum. The general formula for power regression will be derived.

\section{Results}

To display the points in Figure 1, a few companies had to be excluded due to the lack of information in the data file or for the clarity of the chart. 5,077 agricultural companies are shown here. The unknown $\mathrm{x}$-axis shows the debt ratio of individual companies and the $y$-axis their cost of capital. These unknowns are listed in percentages. 


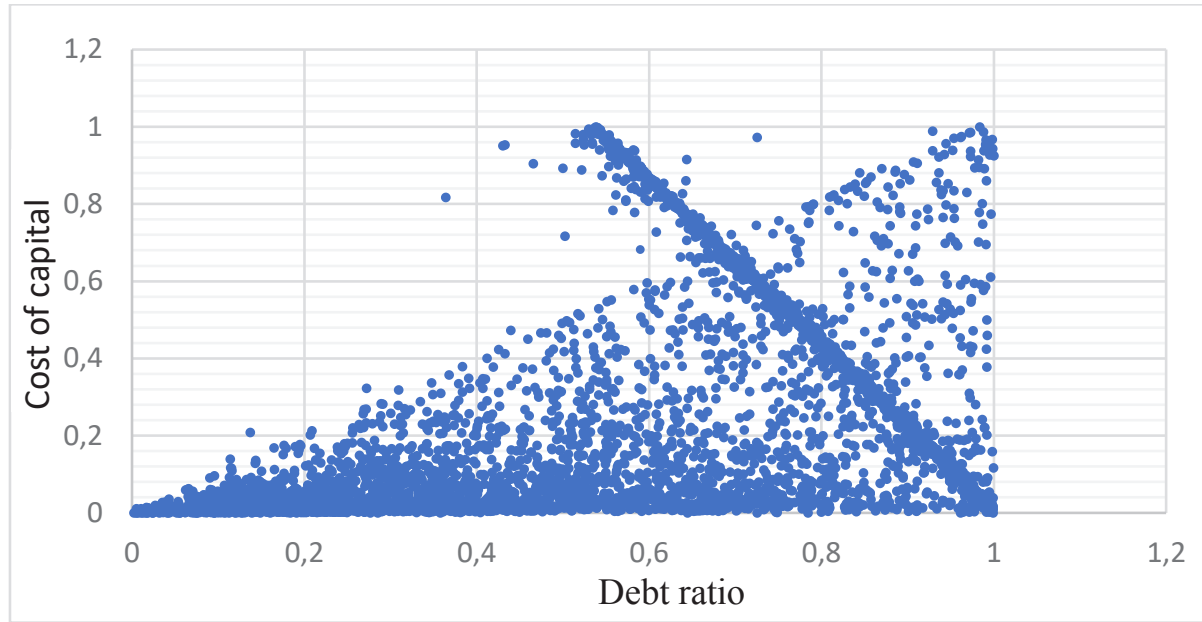

Fig. 1. Relationship between the cost of capital and the debt ratio in a scatter plot Source: Authors.

Using the trendline function in Excel, a power line is displayed. As we can see in Figure 2. This line has a reliability value of $R^{2}=32.02 \%$. The value of reliability determines how two values are dependent on each other. For this example of a pair of values, the debt ratio and the cost of capital. This percentage is not large, so the relationship between the debt ratio and the cost of capital is not reliable in this chart, but is still fair. Next, the equation of the power line: $y=0.2957 * x^{1.3871}$. According to the general formula $y=b_{1} * x^{b 2}$ we derive unknown parameters $b_{1}$ and $b_{2}$. We are not certain that these parameters are already linear for the line or are still nonlinear for the line. So to be sure, we will have to logarithmize the unknown $\mathrm{x}$ and use the LinkRegression function, which gives us the value $\ln \left(b_{2}\right)=1.3871$ and the value $\ln \left(b_{1}\right)=-0.5292$, after de-logarithmizing the value $\ln \left(b_{1}\right)$ we get the value $b_{1}$ $=0.2957$. For the value of $\ln \left(b_{2}\right)$, it comes out to $\ln \left(b_{2}\right)=b_{2}$. Therefore, we will no longer work with this parameter. As we can see here, the equation shown to us by the chart is the same as the one we calculated using the function in Excel.

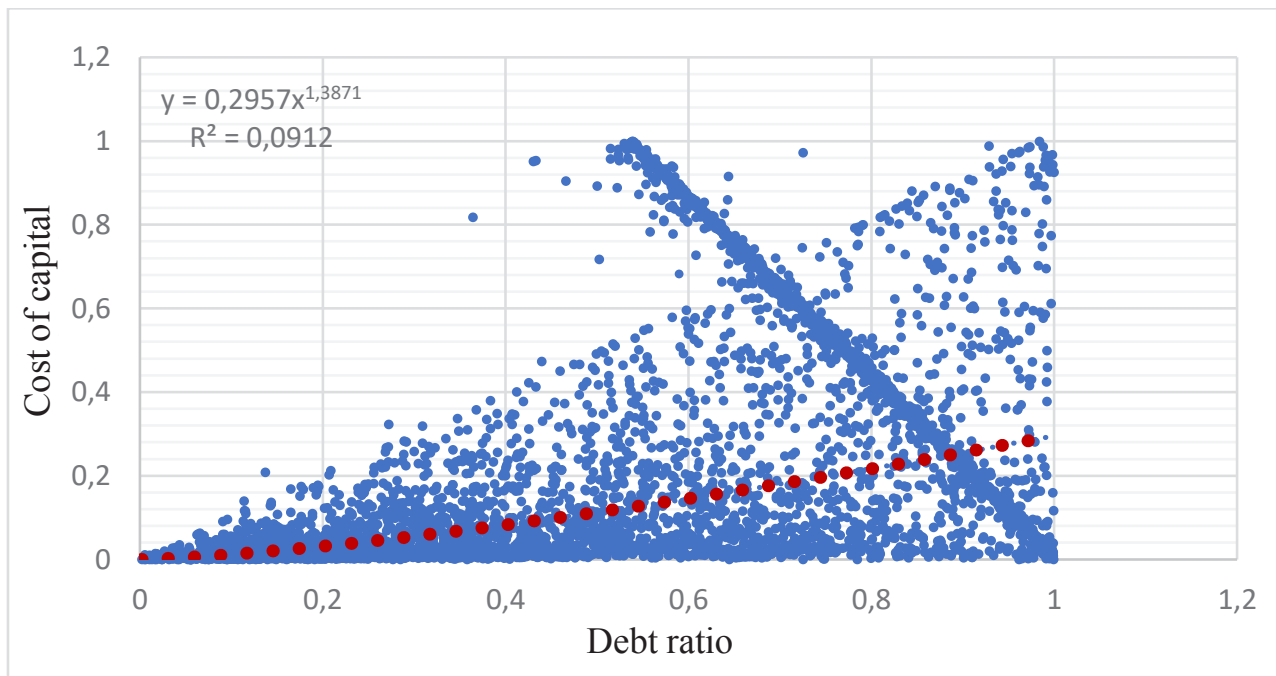

Fig. 2. Power regression in a scatter plot

Source: Authors. 
If we already know the parameters $b_{1}$ and $b_{2}$ for a linear line, we substitute them into the general power equation. So we get the equation: $y=0.2957^{*} x^{1.3871}$. And we differentiate this equation so that we can then calculate the minimum cost of capital. We get the equation:

$$
y^{\prime}=0.41016 * x 0.3871
$$

Using this equation, we can calculate the minimum cost of capital from certain percentages of the debt ratio of individual companies. For this reason, I decided to create a table with the debt ratio from $5-150 \%$ in increments of 5\%. It is shown in Table 1 . In this equation, we can substitute any percentage of the debt ratio of a particular agricultural enterprise to calculate the minimum cost of capital.

Table 1. Minimum cost of capital from a single percentage of debt

\begin{tabular}{|c|c|}
\hline Debt ratio (\%) & $\begin{array}{c}\text { Cost of capital } \\
(\%)\end{array}$ \\
\hline 5 & 12.86 \\
\hline 10 & 16.82 \\
\hline 15 & 19.68 \\
\hline 20 & 22.00 \\
\hline 25 & 23.98 \\
\hline 30 & 25.74 \\
\hline 35 & 27.32 \\
\hline 40 & 28.77 \\
\hline 45 & 30.11 \\
\hline 50 & 31.36 \\
\hline 55 & 32.54 \\
\hline 60 & 33.66 \\
\hline 65 & 34.72 \\
\hline
\end{tabular}

\begin{tabular}{|c|c|}
\hline 70 & 35.73 \\
\hline 75 & 36.69 \\
\hline 80 & 37.62 \\
\hline 85 & 38.52 \\
\hline 90 & 39.38 \\
\hline 95 & 40.21 \\
\hline 100 & 41.02 \\
\hline 105 & 41.80 \\
\hline 110 & 42.56 \\
\hline 115 & 43.30 \\
\hline 120 & 44.02 \\
\hline 125 & 44.72 \\
\hline 130 & 45.40 \\
\hline 135 & 46.07 \\
\hline 140 & 46.72 \\
\hline 145 & 47.74 \\
\hline 150 & 48.00 \\
\hline
\end{tabular}

Source: Authors.

To better compare the debt ratio and the cost of capital, a line chart was compiled. Here we can see how the line of minimum cost of capital increases with higher debt ratio. It shows the point where the line rose. That point shows the debt ratio for the optimal capital structure for the farm, and that is the debt ratio of $23 \%$. 


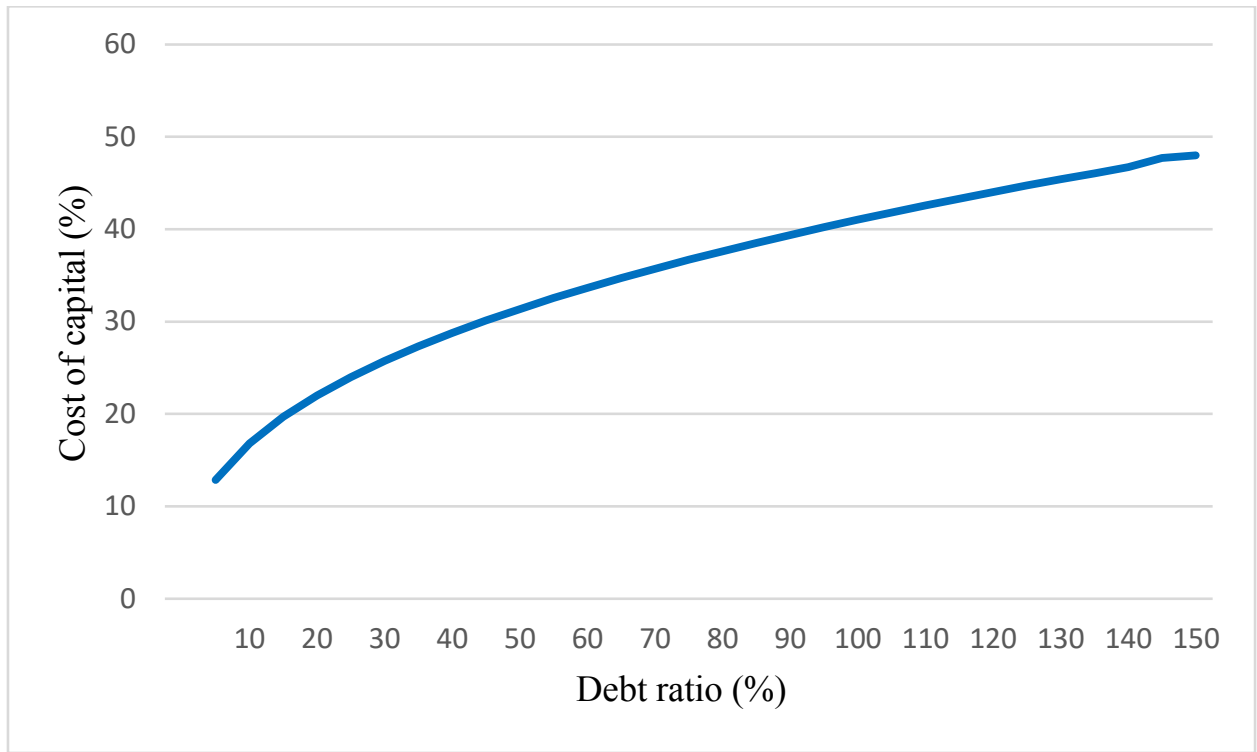

Fig. 3. Relationship between the debt ratio and cost of capital in a line chart Source: Authors.

\section{Discussion}

Based on the obtained results, we can answer the research questions which we have set out earlier:

RQ1: What is the relationship between the price of capital and a company's debt ratio?

The results of Stekla and Grycová [14] showed that all three hypotheses must be rejected because there is a relationship between short-term debt and total assets and profitability, between long-term debt to total assets and profitability, and between total debt to total assets and profitability. Kalusova and Badura [21] found that the negative correlation between total indebtedness and the size of the company, i.e. an increase in the size category of the company is accompanied by a decrease in the company's indebtedness. Only in terms of credit indebtedness, our research shows a positive correlation - so an increase in the size category also leads to an increase in the company's interest rate debt.

RQ2: What is the optimal capital structure?

From Chart 3: Looking at the relationship between the debt ratio and the cost of capital in the line graph, we know that for the optimal capital structure according to the constructed table (see Table 1), the debt ratio is between $20-25 \%$. For this value, the cost of capital shows us $22-24 \%$. In doing so, the company does not use any sales profits or other cash flows.

\section{Conclusion}

The aim of this research was to determine the optimal capital structure for agricultural enterprises in the Czech Republic. Using the WACC method and the debt ratio of individual companies, this goal was achieved. In the results chapter, the individual debt ratios and the cost of capital for individual companies were calculated. Subsequently, they were transferred to a scatter plot (see Figure 1), for which a power line was drawn (see Figure 2). To assess 
the unknowns $\mathrm{x}$ and $\mathrm{y}$, the debt ratio for the unknown $\mathrm{x}$ and the cost of capital for the unknown y were used. Using a function in Excel, the power equation and the reliability indicator were displayed. The reliability indicator showed the reliability of the given equation. To find out if the equation is for a linear or for a nonlinear line, an operation had to be performed, in which the unknown $\mathrm{x}$ and $\mathrm{y}$ had to be logarithmized. Furthermore, the parameters for the linear line had to be calculated with the results of the operation.

After substituting the correct parameters into the general power equation, the equation had to be recalculated using derivation in order to calculate the minimum cost of capital. Furthermore, a table was compiled in the results (see Table 1), where a differentiated equation was used to calculate the minimum cost of capital for various debt ratios. Subsequently, a line graph was drawn on the basis of this table (see graph 3), which determined the optimal combination of debt and cost of capital. In the chapter discussing the results, previously asked scientific questions were answered. The relationship between the cost of capital and the debt ratio of the company was found to exist. The question was also answered: What is the optimal capital structure. We answered it using a table (see Table 1). The results were also compared with other results from previous research by others.

We recommend for entrepreneurs of agricultural enterprises in the Czech Republic that their debt ratio be in the range of 20 to $25 \%$. If an entrepreneur had a debt ratio of above $25 \%$ or below $20 \%$, it would be inefficient for their business. But this interval may not be optimal for all agricultural companies. Because there are many research limits, which could then change the optimal interval. For example, an unbalanced data file, missing data in a data file, other factors that affect the business, such as the size of the business and so on. Also, this debt interval may not be optimal in a year or in 5 years. Therefore, the entrepreneur should take note of this.

\section{References}

1. J. Horák, P. Šuleř, J. Kollmann, J. Mareček, Credit absorption capacity of businesses in the construction sector of the Czech Republic - Analysis based on the difference in values of EVA Entity and EVA Equity. Sustainability, 12(21), 1-16 (2020)

2. J. Horák, V. Machová, Business enterprises and generators of their value. 18th International Scientific Conference on Globalization and Its Socio-Economic Consequences, 547-554 (2018)

3. J. Steklá, M. Gryčová, J. Homolka, Evaluation of capital structure of agricultural cooperatives. AGRIS on-line Papers in Economics and Informatics, 37-48 (2015)

4. L. Frýd, V. Machová, J. Horák, P. Pardal, The wage impact on the net value-added in the agricultural sector. Littera Scripta, 13(1), 186-193 (2020)

5. J. Belás, B. Gavurová, P. Tóth, Impact of selected characteristics of SMEs on the capital structure. Journal of Business Economics and Management, 19(4), 592-608 (2018)

6. J. Kučera, M. Vochozka, Z. Rowland, The ideal debt ratio of an agricultural enterprise. Sustainability, 13(9), (2021)

7. L. Strýčková, Factors determining the corporate capital structure in the Czech Republic from the perspective of business entities. Economics and Management, 40-56 (2015)

8. M. J. P. Lampreia Dos Santos, N. Ahmad, Sustainability of European agricultural holdings. Journal of the Saudi Society of Agricultural Sciences, 19(5), 358-364 (2020)

9. G. Chmelíková, Possibilities and limits for capital structure optimalizing model design of Czech dairy industry. Agriculture Economics - Czech, 48, 321-326 (2002) 
10. C. Russo, D. Weatherspoon, C. Peterson, M. Sabbatini, Effects of managers' power on capital structure: a study of Italian agricultural cooperatives. The International Food and Agribusiness Management Review, 3(1), 27-39 (2000)

11. A. Wolz, J. Fritzsch, The impact of structural social capital on farm income in the Czech Republic. Agriculture Economics - Czech, 52, 281-288 (2006)

12. H. Hudečková, M. Lošták, Social capital in the change of the Czech agriculture. Agriculture Economics - Czech, 49, 301-309 (2003)

13. G. F. Ortmann, R. P. King, Agricultural Cooperatives I: History, Theory and Problems. Agrekon, 46(1), 18-46 (2007)

14. J. Stekla, M. Grycova, The relationship between profitability and capital structure of the agricultural holdings in the Czech Republic. Agriculture Economics - Czech, 62, 421428 (2016)

15. D. Beyer, J. Hinke, European benchmarking of determinants of profitability for companies with accrual accounting in the agricultural sector. Agriculture Economics Czech, 66, 477-488 (2020)

16. V. Fenyves, K. Pető, J. Szenderák, M. Harangi-Rákos, The capital structure of agricultural enterprises in the Visegrad countries. Agriculture Economics - Czech, 66, 160-16 (2020)

17. R. Kieschnick, R. Moussawi, Firm age, corporate governance, and capital structure choices. Journal of Corporate Finance, 48, 597-614 (2018)

18. M. Yen, M. Miranda, A. Katchova, The effects of capital constraints on the growth of agricultural cooperatives. Agriculture Economics - Czech, 66, 27-33 (2020)

19. M. Wysokiński, J. Domagała, A. Gromada, M. Golonko, P. Trębska, Economic and energy efficiency of agriculture. Agriculture Economics - Czech, 66, 355-364 (2020)

20. M. Dimitrova, Financial liquidity of agricultural holdings. Trakia Journal of Sciences, 634-639 (2020)

21. L. Kalusova, P. Badura, Factors determining the financial structure of Czech and Slovak agricultural enterprises. Agriculture Economics - Czech, 63, 24-33 (2017)

22. Y. Wang, The optimal capital structure in agricultural cooperatives under the revolving fund cycles. Agriculture Economics - Czech, 62, 45-50 (2016)

23. J. Špička, P. Dereník, How opportunity costs change the view on the viability of farms? Empirical evidence from the EU. Agriculture Economics - Czech, 67, 41-50 (2021)

24. A. Zeshan, The effect of corporate governance on cost of capital in agriculture sector of Asian countries. Scientific Papers-Series Management Economic Engineering in Agriculture and Rural, 1, 33-40 (2020)

25. Ł. Kryszak, M. Guth, B. Czyżewski, Determinants of farm profitability in the EU regions. Does farm size matter? Agriculture Economics - Czech, 67, 90-100 (2021) 